\title{
Erratum to: The Influence of Aging on Hepatic Regeneration and Early Outcome after Portal Vein Occlusion: A Case-Control Study
}

\author{
Nadia Russolillo ${ }^{1}$, Francesca Ratti ${ }^{2}$, Luca Viganò ${ }^{3}$, Serena Langella ${ }^{1}$, Federica Cipriani ${ }^{2}$, Luca Aldrighetti ${ }^{2}$, and \\ Alessandro Ferrero ${ }^{1}$ \\ ${ }^{1}$ Department of General and Oncological Surgery, Ospedale Mauriziano "Umberto I", Turin, Italy; ${ }^{2}$ Liver Unit, \\ Department of Hepatobiliary Surgery, San Raffaele Hospital, Milan, Italy; ${ }^{3}$ Liver Surgery Unit, Department of Surgery, \\ Humanitas Clinical and Research Center, Rozzano, Milan, Italy
}

\section{ERRATUM TO: ANN SURG ONCOL DOI 10.1245/S10434-015-4478-3}

In the initial online publication, the authors' family names and first names were interchanged. The names have been corrected in the publication as shown in this erratum.

The online version of the original article can be found under doi:10. 1245/s10434-015-4478-3.

(C) Society of Surgical Oncology 2015

Published Online: 23 April 2015

N. Russolillo

e-mail: nrussolillo@mauriziano.it 